\title{
Oralidade e identidade étnica: a Comunidade Quilombola de Massapê, município de Carnaubeira da Penha (PE)
}

\section{Orality and ethnic identity: the Quilombola community of Ong, municipality of Carnaubeira da Penha (PE)}

\author{
Geraldo Barboza de Oliveira Junior \\ Instituto de Desenvolvimento, Educação e Planejamento Ambiental - IDEA-RN \\ e-mail: geraldoboj1963@gmail.com
}

\begin{abstract}
Resumo
Este texto objetiva mostrar a comunidade Quilombola de Massapê, em Carnaubeira da Penha, Estado de Pernambuco que, mesmo, após sua certificação pela Fundação Cultural Palmares em 08 de março de 2005, ainda, enfrenta dificuldade em obter reconhecimento social e acadêmico. A base empírica é o relatório antropológico de identificação elaborado no âmbito do Projeto de Integração do rio São Francisco. Aqui se analisa o relatório antropológico de Massapê objetivando contribuir ao conhecimento acadêmico dessa realidade social. A abordagem metodológica foi integrada por pesquisa bibliográficodocumental e uma pesquisa de campo para a elaboração de um relatório antropológico; que se constituiu de diversas reuniões, iniciais, com a comunidade, na realização de entrevistas (gravadas em arquivo digital) e fotos. O debate teórico sobre memoria, oralidade, invisibilidade, quilombo e etnicidade direciona esta análise. Se conclui que a adoção da categoria quilombola entre os moradores do Massapê é recente. A afirmação de ser quilombola ou não se baseia na ancestralidade negra e nas relações de vizinhança com povos indígenas.
\end{abstract}

Palavras-chave: Quilombolas, Massapê, Relatório Antropológico.

\begin{abstract}
This text aims to show the quilombola community of Ong, Carnaubeira da Penha, Pernambuco state that, even after its certification by the Palmares Cultural Foundation on 08 March 2005, still face difficulty in obtaining social recognition and academic. The textual basis of this article is the anthropological Report of identification of this community developed in the framework of the Integration Project of the São Francisco River. Here we analyze the anthropological report of Ong aiming to contribute to the academic knowledge of social reality. The methodological approach was integrated by bibliographic research-documentary and field research; which consisted of various meetings, initials, with the community, in the interviews (recorded in digital file) and many fotos. The theoretical debate about memory, orality, invisibility, quilombo and ethnicity directs this analysis. If it concludes that the adoption of the quilombola category among the inhabitants of the Ong is recent; however, fragile. The statement to be AfroBrazilian or not based on black ancestry, and at the present moment - in which the territory is neighbor of indigenous communities (which has a more significant political advantages) this is reconsidered.
\end{abstract}

Keywords: Quilombolas, Roberts, Anthropological Report. 


\section{Introdução}

Neste artigo se retoma o relatório antropológico que abordou a história, demografia, economia e organização da comunidade quilombola de Massapê, localizada no município de Carnaubeira da Penha, Estado de Pernambuco. Esta comunidade foi incluída no coletivo de comunidades impactadas pelo Projeto de Integração do Rio São Francisco (PISF) e é objeto de um Programa de Compensação Ambiental quilombola (PBAQ). Este programa tem por objetivo:

Apoiar o processo de reconhecimento e garantia territorial das comunidades que se autodefinem como quilombolas situadas na área de influência direta do empreendimento, através do estabelecimento de uma parceria entre o Ministério da Integração Nacional e o INCRA/MDA, com a alocação de recursos para identificação, delimitação e regularização fundiária dos territórios quilombolas.

Promover o desenvolvimento destas comunidades, através da implantação de infraestrutura de saneamento básico, educação, saúde, transportes etc (PBAQ, 2017, pp. 4).

A ausência de levantamentos estatísticos oficiais que permitam 0 mapeamento das realidades negras rurais, seu montante e distribuição geográfica, condição social de vida ou até mesmo a realidade econômica, têm contribuído para a invisibilidade desse segmento rural. Outras ausências, como análises mais profundas do legado da escravidão e o desconhecimento do sentido e do significado da terra e do trabalho para os diversos grupos rurais, agravam ainda mais esse quadro (Gusmão, 1995:12).

A invisibilidade tem se constituído como um mecanismo sutil de exercer o racismo à brasileira. Não se fala porque se desconhece. Não se conhece porque não é interessante mostrar. Não se mostra porque não se deseja. Para Leite (1996:41):

$A$ invisibilidade do negro é um dos suportes da ideologia do branqueamento, podendo ser identificada em diferentes tipos de práticas e representações [...]. É interessante observar que este mecanismo [...] ocorre em diferentes regiões e contextos, revelando-se como uma das principais formas de o racismo se manifestar. Como um dispositivo de negação do outro, muitas vezes inconsciente, é produtor e reprodutor do racismo. A invisibilidade pode ocorrer no âmbito individual, coletivo, nas ações institucionais, oficiais e nos textos científicos. 
No caso específico das comunidades quilombolas, "a produção científica existente sobre as comunidades negras em situação de vida rural ainda é escassa, o que as coloca entre os temas em aberto no estudo das relações raciais" (Bandeira, 1988, p. 319). Assim, torna-se imperativo que sejam estimuladas pesquisas que visem à promoção das populações negras às conquistas inerentes ao seu espaço político na sociedade brasileira.

É fundamental ao se recuperar a textualidade de uma época avaliar-se a coexistência temporal. A descontinuidade do tempo é patente na relação dialógica que o sujeito do discurso estabelece com suas memórias. Esta, na prática discursiva, torna-se textos presentes que, por sua vez, inscrevem-se na intertextualidade que envolve a produção textual como prática social (Rapchan, 2001, p. 66).

O que caracteriza Massapê em termos de registros históricos é a ausência destes. Esta comunidade está na categoria de comunidade invisível e invisibilizada na literatura histórica regional. Por isso, a utilização da oralidade e as memorias como recurso metodológico mais conveniente à reconstrução da sua história.

\section{Metodologia}

O relatório antropológico foi realizado no $1^{\circ}$ semestre de 2009, iniciamos nosso contato com as comunidades de remanescentes de quilombos acompanhando os técnicos do Ministério da Integração em diversas reuniões nos municípios com seus representantes. No caso de massapé, realizamos, em seguida, uma reunião na própria comunidade para expor o trabalho a ser desenvolvido. Após esta visita, foram iniciadas conversas com colegas antropólogos (em especial, os da FUNAI) em busca de orientação de como melhor proceder para realizar um trabalho de pesquisa antropológica dentro dos referenciais da Instrução Normativa No. 49. A opção foi pela constituição de uma equipe multidisciplinar. Compomos esta com um antropólogo e duas historiadoras em período integral e, oportunamente, tivemos a colaboração de um geógrafo, pedagoga, de engenheiros agrônomos, ambientais e florestais. Conversas profícuas com profissionais da Biologia, do Direito, da Educação Ambiental, entre outros fizeram parte do cotidiano da Pesquisa.

Foram realizadas diversas visitas na comunidade (em um período de dois meses) nas quais identificamos e entrevistamos os informantes de maior interesse para o nosso trabalho: os mais idosos, o presidente da Associação de Remanescentes de Quilombos de Massapê, a auxiliar de serviços gerais 
que atua na escola (que tem o curso de magistério) e mantém na sua casa uma "biblioteca" do Programa Arca das Letras, um vizinho (branco) que manteve uma farmácia na vila comercial de Massapê, pessoas da cidade (secretários municipais, ex-professoras da escola de Massapê, quilombolas de Massapê -residentes em Carnaubeira da Penha e em Floresta). Visitamos secretarias municipais em busca de documentos, visitamos, também, a Ordem das Missionárias Rainha da Paz (onde conhecemos o acervo fotográfico do Padre Evaldo Betti e tivemos acesso a fotos antigas do Massapê).

Anterior às visitas na comunidade de Massapê, com o auxílio de duas historiadoras, fizemos uma pesquisa bibliográfico-documental na internet na busca de dados gerais sobre os municípios; estas mesmas historiadoras, vinham já há tempos transcrevendo textos da área de antropologia relacionados à questão quilombola e de laudos antropológicos. Obtivemos também documentários regionais em livros e um vídeo sobre os quilombos de Pernambuco; estes foram realizados pelo Centro Luís Freire (uma ONG que trabalha no apoio às comunidades quilombolas de Pernambuco) em parceria com a Coordenação Estadual de Articulação das Comunidades Quilombolas e com a Associação da Comunidade Quilombola de Conceição das Crioulas.

As 23 entrevistas, gravadas em gravador digital, totalizaram cerca de 05 horas. Como recurso auxiliar, fizemos, em todas as viagens, o registro fotográfico das pessoas sendo entrevistadas e do meio ambiente. A transcrição das entrevistas e a posterior leitura crítica possibilitaram a observação das lacunas de informações que nos faltavam.

Foi realizado o reconhecimento da área do território quilombola de Maassapê através de caminhada (das 08:30h às 12:15h) guiada pelo Sr. Joel Salvador, de 82 anos um morador local que se dispôs a acompanhar a equipe em seus vários momentos de identificação de limites geográficos da comunidade.

Realizamos diversas visitas aos quilombolas residentes no município de Floresta, onde estão sob a liderança de Dioclécio Nogueira (bisneto do fundador do Massapê). Entrevistas gravadas e fotografias fizeram parte destes momentos. Isto, entretanto, foi ampliado por uma orientação àquela população em relação à sua organização social enquanto quilombolas expatriados de sua comunidade e reagrupados em uma área urbana, Massapezinho. As dúvidas eram muitas - e alimentadas pela comunicação informal entre os moradores de Massapezinho e Massapê. Uma verdadeira "guerra psicológica" entre as duas comunidades, que requereu uma 
sensibilidade maior dos pesquisadores nos momentos de coletar e sistematizar as informações.

\section{A Comunidade de massapê.}

A comunidade de Massapê está localizada entre o riacho Grande, a Serra do Arapuá, a Terra dos indígenas Pankarás e as Terras de Manoel Neto. No mapa no mapa elaborado pelos Pankará, figura 1, Massapê foi localizado fora dos limites dessa terra indígena. Massapê abriga as casas e as vilas, tem cerca de 236 hectares de extensão. Entretanto, a comunidade possui ainda terras que estão situadas na área anterior ao Riacho Grande até o topo da Serra do Arapuá.

Figura 1. Mapa do Território Indígena Pankará.

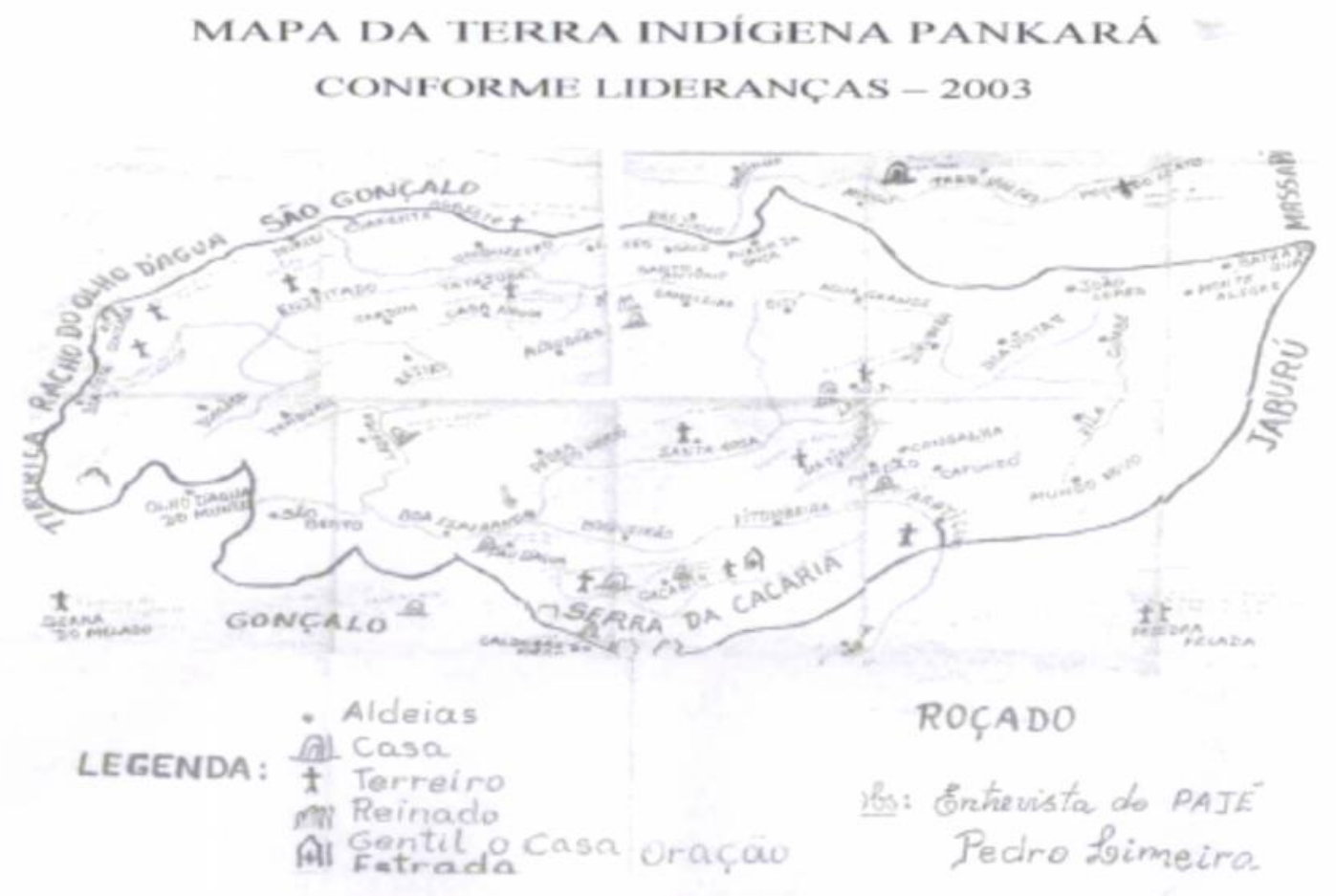

Fonte: Pankará (2003)

O acesso a Massapê é por uma estrada em leito natural que liga Carnaubeira da Penha ao município de Floresta (PE). Após sair da cidade, nesta estrada, depois de 10 quilômetros entra-se à direita, e após mais 04 quilômetros chega-se à Massapê. A estrutura física de Massapê, em 2009 quando realizamos o relatório antropológico, evocava uma lembrança de 'cidade fantasma'. O abandono e desolação marcam o cenário de uma vila inteira de casas destruídas. O prédio da escola revela paredes com pintura em atraso, esquadrias caindo e teto precisando de reparos. O cemitério e a 
construção física da igreja denunciam desamparo, indicando não ser mais locais de cerimônias. A seguinte fotografia mostra as edificações que remetem ao que fora no passado o epicentro comercial da comunidade.

Figura 2. 'Vila Comercial' de Massapê

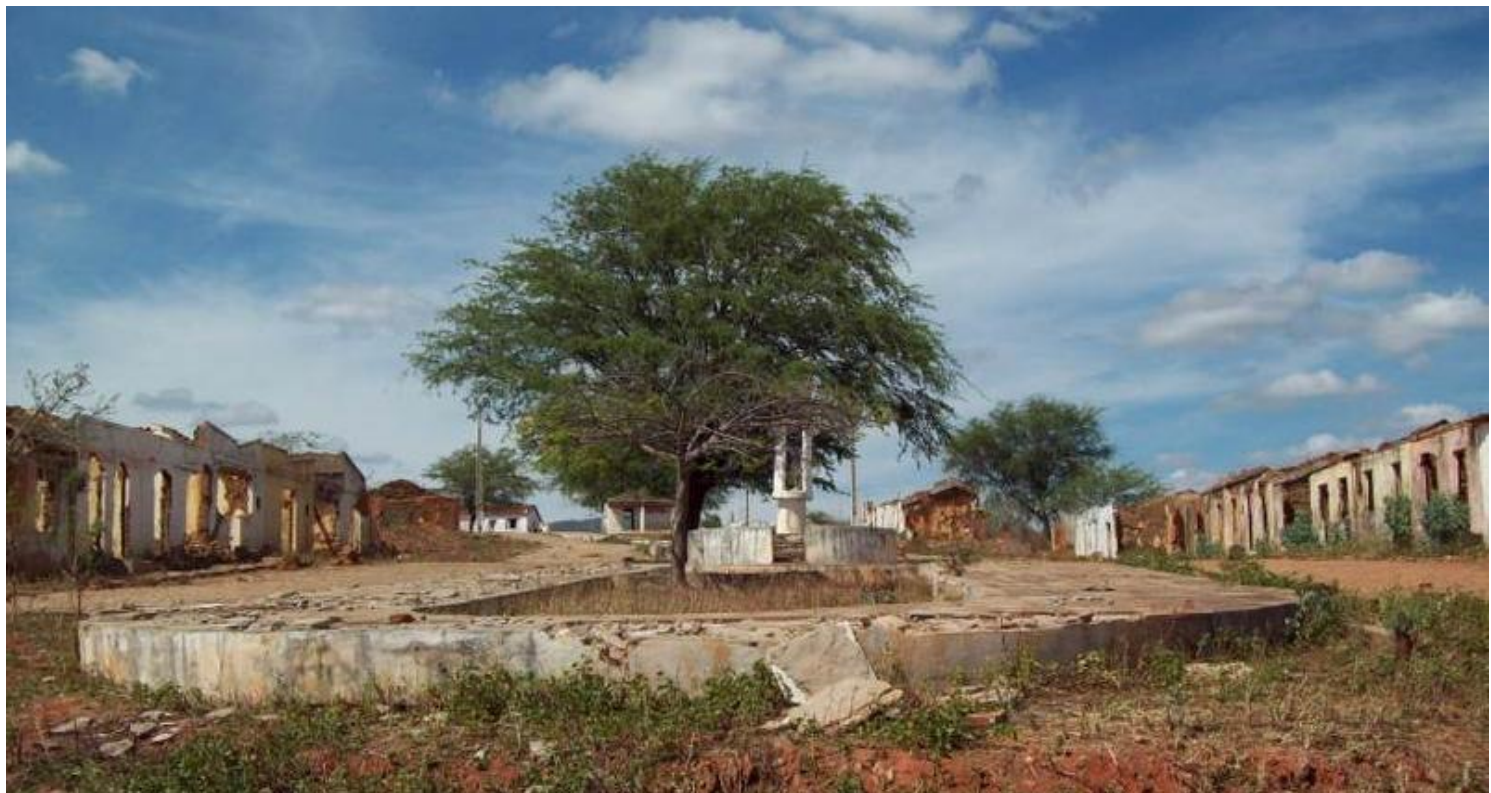

Fonte: arquivo pessoal.

A economia atual de Massapê está sustentada nas aposentadorias, nos benefícios sociais como bolsa família e merenda escolar, e, ainda, na prática de agricultura de feijão e milho sazonais, durante o período das chuvas. A falta de água é uma constante na comunidade. Existe um abastecimento domiciliar quinzenal ou mensal mediante cisternas de placas. Entretanto, existem reclamações, por parte de vários moradores, de que esse serviço não atende todas as famílias.

As atividades sociais de cunho religioso são pouco expressivas em Massapê. Em 2009, se retomou à realização da 'novena' que trata da comemoração católica realizada no mês de novembro em homenagem à padroeira da comunidade. Outras práticas culturais foram abandonadas pela comunidade, como a Dança de São Gonçalo e o Xangô cuja religiosidade afro-brasileira no local tem um componente indígena bastante forte: o Toré.

Essas festas formam uma lembrança do passado e pareciam relativamente ignoradas pela juventude local. Tudo corrobora para dar uma imagem de passado próspero, porém, distante. A visão e os discursos dos entrevistados pouco contribuem para se acreditar no retorno desse passado, para alguns muito distante. Para Francis Fukuyama, ao tratar de capital social, a religião... 
[...] continua sendo uma importante fonte de regras culturais, mesmo em sociedades aparentemente seculares: ao mesmo tempo, regras religiosas estão sujeitas a uma evolução espontânea, na medida em que interagem com um determinado ambiente histórico. Entender essas relações, $e$ fornecer um mapa empírico das fontes de regras culturais reais, é um projeto para o futuro (Harrison e Huntington, 2002:171).

O recurso da história oral como forma de construir a história local, "dos pequenos", do cotidiano dos moradores vem de encontro a uma necessidade de legitimar a memória como uma construção histórica. A ausência de dados a respeito das comunidades quilombolas é algo que, de maneira incipiente, ainda revela hiatos na história deste segmento da população brasileira. Entendemos ainda que:

Os trabalhos que fazem uso da narrativa como fonte principal de reflexão precisam ser pensados no contexto metodológico particular na medida em que colocam o sujeito-narrador, 0 conteúdo narrado e o ouvinte, o pesquisador, no centro da questão. Neste sentido, não escapa das discussões teóricas, metodológicas e epistemológicas próprias às ciências sociais referentes à relevância ou não do sujeito como parâmetro de análises acerca da cultura, da sociedade e da história (Rapchan, 2001, p. 47).

De forma geral, a história de Massapê aqui descrita se sustenta na oralidade dos seus moradores que lembram ameaças e deslocamentos territoriais. De acordo com Dioclécio Vicente, liderança de Massapê, outros líderes foram "expulsos" da terra e hoje mora em Nova Florest. A formação de Massapê começou com a compra de uma gleba de terra pelo bisavô de Dioclécio, Jacinto Nogueira. Segundo ele, veio da serra de Baixa Verde e sua esposa da serra de Umã. Em seguida, uma outra família negra adquiriu também terras no Massapê: a família Salvador. Esta informação é corroborada pelo diagnóstico realizado pelo Ministério da Integração à época dos estudos e relatórios de impacto ambiental das obras da Transposição do São Francisco, ao citar que:

A comunidade foi iniciada através do patriarca Jacinto José da Silva que migrou da Paraíba por volta do ano de 1850. A comunidade prosperou bastante chegando a se tornar o maior distrito do município de Carnaubeira da Penha. Aos finais de semana era realizada uma espécie de feira regional onde além 
do comércio eram desenvolvidas atividades culturais de música, dança, comidas típicas, etc. O destino da comunidade foi drasticamente mudado há cerca de 7 anos quando uma briga entre negros da comunidade e brancos de fora provocaram grande carnificina com a morte de aproximadamente 10 pessoas (entre negros e brancos). Após o ocorrido o vilarejo foi abandonado e grande parte das pessoas foram embora para o município de Floresta temendo outros incidentes. Hoje a população do lugar vive espalhada em propriedades esparsas e restou uma pequena cidade fantasma onde as ruínas são testemunhas da tragédia bem ao estilo cangaço ou velho oeste americano.

Segundo os registros orais, até os anos 60 do século XX não houve mudanças significativas na comunidade. A vida dos moradores era baseada na agricultura com o cultivo do algodão, do feijão e do milho. Praticavam ainda a coleta de umbu e a fabricação de telhas para venda e para uso próprio. A utilização de artefatos de palha veio com o convívio com os indígenas Pankarás, e, fazia parte do cotidiano. As esteiras eram parte da decoração das casas e, junto com os potes, também constituíam objetos para comercialização nas feiras locais.

Os fatos que culminaram na expulsão dos moradores do Massapê são falados numa ordem sem maiores preocupações cronológicas. Porém, vivos na memória de todos. Assim, alguns fatos constituem a "vida lembrada" de Massapê. Nos anos de 1960: a construção da escola pela prefeitura. Nos anos de 1970, a instalação da feira e a construção de uma vila comercial. Nos anos 1980: a construção da Capela de Santa Luzia pelo Padre Evaldo Betti (1987), do Posto de Saúde e do Posto Telefônico. Nos anos 1990: a formação da Primeira associação de agricultores de Massapê e Queimadas.

Na virada do século XX para o século XXI, vários fatos constroem a visão atual de Massapê: as mortes de vários moradores locais que teve seu ápice na noite da destruição das casas e da fuga a pé, na madrugada, das famílias para Floresta. $\mathrm{O}$ abandono e a destruição de casas e da vila comercial são desdobramento desse fato. Em 2007 a formação de uma nova associação local, a certificação da comunidade pela Fundação Cultural Palmares e a inclusão do Massapê no rol das comunidades quilombolas a serem beneficiadas pelo Programa de Apoio às Comunidades Quilombolas do PISF. Percebemos que:

Através da memória individual, será possivel recuperar a memória coletiva de um período sobre o qual existe muito 
pouca documentação. Essa história além de contribuir para o melhor conhecimento da comunidade (BECKER, In: Montenegro e Fernandes, 2001, p. 286)

No entendimento dos moradores, a história de Massapê teima em se firmar na noite da tragédia que se desdobrou na migração forçada para Floresta. Esse deslocamento culminou com uma diáspora dos moradores locais que não viram sequer o estabelecimento de um processo jurídico para esclarecer a responsabilidade dos assassinatos ocorridos nessa noite. Uma história que não foi escrita e faz questão de não ser esquecida pelos moradores locais. Como disse Dioclécio: "pronto, eu não estava lá, mas eu sei. Porque foram roubar lá dentro do Massapê, três caras trajando um tenente de galão no braço e outros de policiais entendeu?" (Entrevista, Massapê, 2009).

Ao perguntar sobre detalhes da "noite do crime" ele, Dioclécio, resumiu assim os fatos:

Chegaram lá de noite e metero bala, o povo tudo assistino ná televisão, o povo que fica no meio da rua, bota as mãos pra cima que é a puliça, Tinha um subrinho meu, muito experiente na lengada, curiou, assim viu que não era puliça dobrou o pé, aqui pegou uma arma e desceu, quando desceu derrubou um, entendeu?

E num derrubou os outros porque agarraro em meu irmão e pra todo canto que ele butava a arma jogavam meu irmão na frente das armas, e puxando e tirando, até que derrubou ele, aí mode isso daí, porque esse que morreu era de lá que ele veio trajado de tenente, veio pra peda entendeu?

E por isso aí juntou meio mundo pa mata meio mundo de gente, mataro um doidinho lá, um abestalhadim né? Mataro lá, depois vinhero e mataro o irmão dela encostado a cadeia, aí só foi isso aí, começou por isso, por um nada (Entrevista, Massapê, 2009).

A relação da história dos moradores locais com um território, no sentido de ocupação coletiva, é uma constante no discurso local. As terras são faladas como terras de proprietários em particular. Em especial, as terras dos Salvador ${ }^{1}$ e dos Vicente $^{2}$ Terras compradas, individualizadas e deixadas

\footnotetext{
${ }^{1}$ Terras dos familiares de Joel Salvador.

${ }^{2}$ Terras dos familiares do Dioclécio Vicente.
} 
como herança. "Tudo escriturado em cartório!" (Entrevista Dioclécio, Massapê, 2009).

A divisão das terras das famílias dos descendentes de Dioclécio constituem, paradoxalmente, categoria de pertencimento ao Massapê. Outras famílias, em especial a de Glaudiovani, são vistas como exógenas à categoria de ser do Massapê. Isto pelo fato de que este comprou uma parte de terras do finado Adriano (um morador pertencente às famílias tradicionais do Massapê, já falecido). Vale salientar que esta compra não teve valor legal e os descendentes de Adriano, questionam esta negociação. Nesta terra, Glaudiovani construiu uma casa e articulou o processo de fundação da Associação Quilombola de Massapê e é o presidente desta.

A presença, nos relatos, desta incansável capacidade de reagir, através da recusa das diferentes situações de humilhação e de conflito, aponta para a reconstrução de uma historicidade, de uma autoimagem como 'raça forte', que o medo se enfrenta ao tomar a frente, quando deparado com o seu maior desafio: ser ignorado na sua condição de humanidade, no valor de sua existência (CHAGAS, in. LEITE, 2005, p. 75)

Nessas memorias sobre a história de Massapê prima a exposição da noite das mortes e da fuga para Floresta. Essa noite se constrói como o fim e o começo da nova história e do ciclo de vida. Reconstruir a História de Massapê passa, inevitavelmente, pela persistência da memória de seus moradores em trazer à tona um assunto não resolvido. Ninguém foi penalizado judicialmente. Tudo ficou apenas na memória.

\section{A invisibilidade de Massapê}

Para exemplificarmos essa invisibilidade histórica de Massapê citamos duas produções literárias que tratam de temas pertinentes à história de Massapê. O livro "Sertão quilombola: a formação dos quilombos no sertão pernambucano" (2008) e a apostilha "Conhecendo melhor o nosso município" (2002) que trata de Carnaubeira da Penha sob os pontos de vistas históricos e geográficos. Esta literatura ignora Massapê e/ou trazem dados que estão em conflito com as informações obtidas.

O livro "Sertão quilombola", publicado em 2008, de maneira geral, trata dos fluxos migratórios e rotas de fugas que originaram comunidades quilombolas. Neste, as comunidades estão divididas por regiões de desenvolvimento: sertão Central, de Itaparica, do Moxotó, do Pajeú e do São Francisco. São listadas 40 comunidades quilombolas. Não é citada a comunidade de Massapê. Em relação a Massapé somente existem duas 
referências quando tratam das origens de duas comunidades de Mirandiba: Araçá e Juazeiro Grande.

Citam como fundador do Araçá o negro João Balbino. "Era filho de Maria Josefa Balbino. Eram originários de Massapê, no município de Floresta". Em relação a Juazeiro Grande "habita a família dos Henrique dos Galdino. É da família dos Henrique que descende o negro Manuel.... Manuel veio da descendência do Massapê (Carnaubeira) da família dos Virgínio"(ARARIPE e NASCIMENTO, 2008, pp. 18-30). Somos instigados a levantar uma dúvida sobre o conteúdo do que está escrito. Em nenhum momento, soubemos da existência, na memória, dos habitantes locais, das pessoas citadas. Isso, obviamente, não caracteriza como inverdade o que foi citado, porém, merece mais investigações.

A apostilha "Conhecendo melhor o nosso município", publicada em $2002 \mathrm{faz}$ referências aos brancos e indígenas na constituição do mosaico étnico local. Não há referências às pessoas negras como parte constituinte da historiografia local. A palavra 'negro' vem uma única vez na citação: "Negros ou mulheres vulgares não podiam dançar juntos com as moças de famílias, as brancas". Esta apostila é utilizada no ensino de estudantes da $5^{\mathrm{a}}$ à $9^{\mathrm{a}}$ séries no curso de história sobre o município.

Esta situação mostra, cabalmente, a invisibilidade histórica e literária na qual Massapê está mergulhada. Por seu turno, as pessoas de Massapê têm guardados, como tesouros, os documentos de compra de suas terras (ver figura 3). Comprovantes escritos no contexto de uma história que persiste através da oralidade. Nas disputas territoriais esses documentos oficias com caráter jurídico são chaves para legitimar as memorias recriadas pela história oral. 


\section{Figura 3. Documento da Terra do Senhor Joel Salvador}

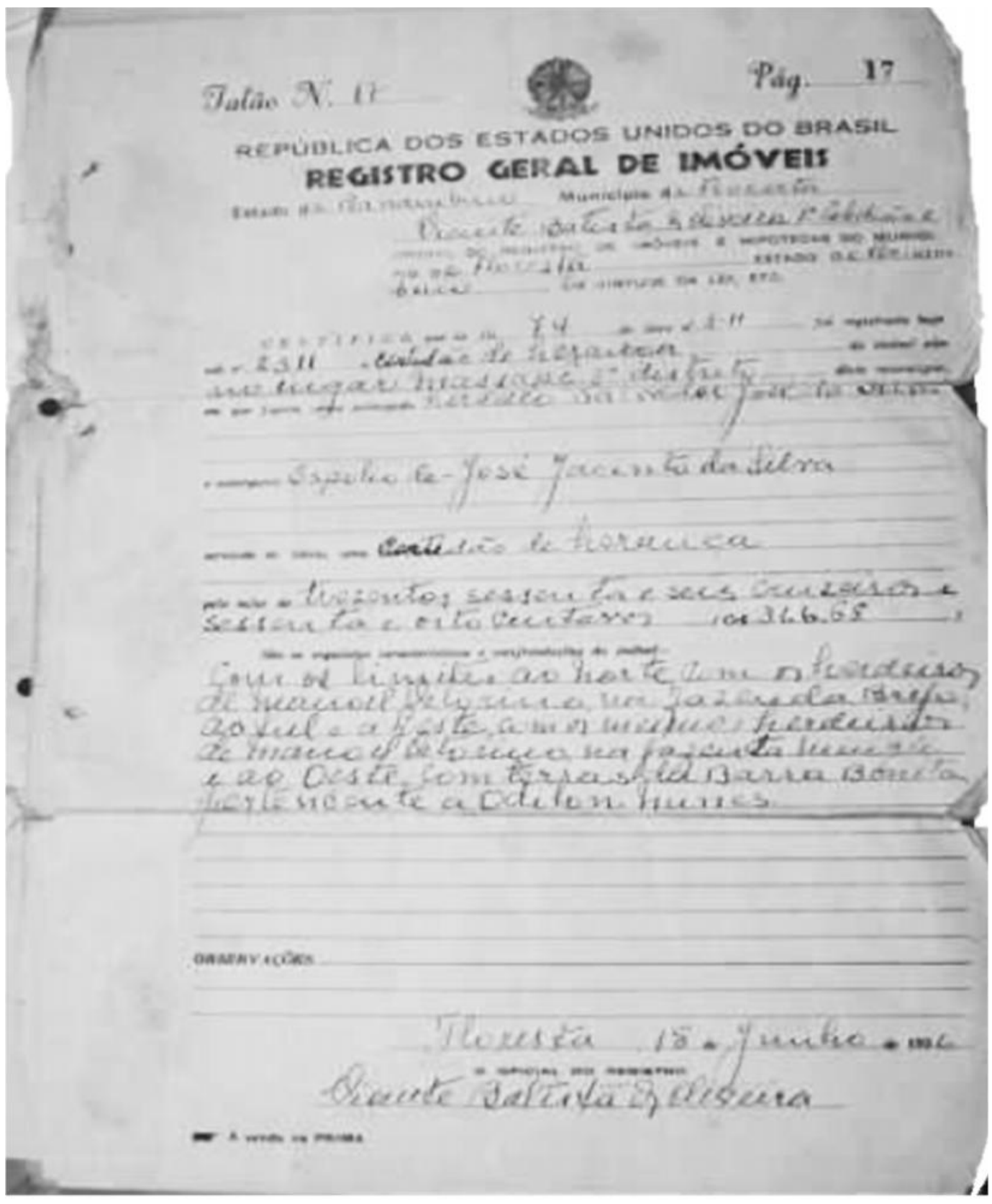

Fonte: arquivo pessoal.

\section{No patrimônio Cultural ${ }^{3}$ de Massapê pode-se citar bens naturais como a caatinga que é expressiva como paisagem local. $\mathrm{O}$ riacho Grande que}

\footnotetext{
${ }^{3}$ A concepção atual de patrimônio cultural implica em uma divisão deste em quatro categorias. Assim: "Há os bens naturais, que são os elementos pertencentes à natureza: animais, vegetais e minerais. São recursos naturais os rios, os vales, as montanhas etc. os bens de ordem material são as criações dos homens visando aumentar seu bem-estar social, familiar, sua vida, e adaptar-se ao meio em que vivem. São bens materiais as coisas, os objetos, as construções etc., realizadas pelo homem. Os bens de ordem intelectual, são os "saberes" do homem. O conhecimento ou o saber que o homem utiliza na construção de um objeto é um exemplo de bem de ordem intelectual. Os bens de ordem emocional representam o sentimento individual ou coletivo - são as manifestações folclóricas, cívicas, religiosas e artísticas, eruditas e populares que se expressam por intermédio da música, da literatura, da dança etc" (ATAÍDES et al, 1997, pp. 11-12). Enfim, o patrimônio cultural atesta a história de uma determinada sociedade, ou seja, tudo que se refere à identidade, à ação, à memória de uma sociedade.
} 
depende das chuvas de inverno para mostrar sua pujança. A serra do Arapuá que é limite das terras do território do Massapê. O solo com características diversas: ora pedregoso, em sua maioria, ora com a presença forte de massapé (barro bom para plantio), áreas de baixio propícias para o plantio de árvores frutíferas. Enfim, a caatinga expondo uma diversidade que sai do conceito geral que lembra a aridez do sertão como uma qualidade homogênea.

Os bens de ordem material do Massapê configuram-se como uma lembrança pretérita. A vila de casas destruídas, o cemitério abandonado, a igreja necessitando de reformas, a casa de farinha abandonada somente com suas paredes, e as casas abandonadas. A escola precisando de reformas estruturais, contudo funciona da $1^{\text {a }}$ à $4^{\text {a }}$ Séries do ensino fundamental em uma única sala. E inexiste fornecimento de água potável e eletricidade, e, mesmo os banheiros foram destruídos.

Os bens de ordem intelectual referentes à população de Massapê incluem as rezadeiras, o conhecimento sobre a flora e a fauna local, sobre os ciclos de chuva e de seca, sobre o trato com os animais. Os moradores mais velhos sabem do potencial fitoterapêutico das plantas e, onde estas podem ser localizadas. Os jovens ignoram este potencial e passam, por sua vez, a depender mais de valores e conhecimentos urbanos.

\section{Território e identidade do massapê}

Segundo os dados do agente de saúde local, no Massapê existem 79 moradores distribuídos em 18 famílias residentes. Após consulta aos moradores soubemos do retorno de aproximadamente 05 famílias, ainda não definidas se de forma sazonal ou perene. É comum o retorno de pessoas que residem em Floresta para trabalhar em suas terras no período de chuvas. Entretanto, soubemos de pessoas que estão voltando "de vez" para Massapê na expectativa das possibilidades que podem surgir no PISF: escola, posto de saúde, telefonia, etc., e, também, cansados de uma vida de pouca perspectiva em Floresta.

Na época das chuvas as terras têm ocupação restrita para o plantio de feijão e milho. Em algumas vazantes é plantado capim para gado bovino e cavalos. Em alguns casos existe arrendamento de terras para o plantio de inverno. Em uma caminhada pela área de Queimadas ${ }^{4}$ que é ocupada pelos familiares de Dioclécio Vicente, portanto território Massapê, ficou constatado que grande parte das terras foi roça de mandioca no passado.

${ }^{4}$ Área localizada antes do riacho Grande que se configura como marco definidor de limites. 
Hoje, o mato, no período de inverno ocupa a maior parte das terras. A ocupação e utilização das terras do Massapê está quase restrita à área das margens do riacho Grande e da vazante do açude. Nos baixios onde se acumula umidade há arvores de mangas. Esta oferta, porém, não representa acréscimo na economia das famílias.

A criação de animais, em particular a criação de cabras e ovelhas procura seguir um padrão comum: compram-se estes animais para engordar no inverno e vender no período de secas. Não há uma perspectiva de manter a ovino-caprinocultura independente das variações climáticas. Como também em relação à agricultura estas atividades estão vinculadas as chuvas para produção de pastos 'fáceis'. Por outro lado, a caatinga com o êxodo da população local voltou a se recuperar das queimadas e das áreas roçadas. As casas habitadas e as abandonadas fazem parte do cenário local. Juntamente com os cemitérios particulares, também, abandonados.

O medo do retorno, aliado à presença de ameaças veladas através de telefonemas anônimos faz com que alguns moradores desistam de manter uma presença mais consistente no trato de suas terras. No geral, estas ameaças estão relacionadas a alguns familiares de Dioclécio Vicente. Não se observou, como em outras localidades, organização social em torno da igreja, ou de mães, jovens ou idosos.

Os estudos antropológicos de Fredrik Barth, nos anos 60, apontam que os fenômenos étnicos daquela época estavam assumindo visibilidade social e política no mundo inteiro, em razão das diversas dificuldades que os grupos vinham apresentando. Barth introduziu uma visão dinâmica da identidade étnica construída e transformada na interação de grupos sociais, incluindo e excluindo grupos ao estabelecerem limites entre si, definindo os que integram ou não. Essa visão barthiana foi aperfeiçoada posteriormente por Smith, que considerou "comunidade étnica como uma população nomeada por um mito do ancestral comum, com memórias compartilhadas de elementos culturais, com uma ligação com um território" (1993, 23 apud BROWN, 1999: 28).

Comparando esses conceitos percebe-se que enquanto Barth enfatizou o aspecto biológico do grupo, Smith valorizou a origem comum construída socialmente. Barth valorizou a perpetuação, ou seja, a projeção do grupo étnico para o futuro, enquanto Smith se referiu à ancestralidade comum, ou seja, ao passado da comunidade étnica. Entendemos que a origem e o destino compartilhados, ou a existência da origem ou apenas do destino compartilhado de um grupo, podem ser indicadores na sua identificação como grupo étnico. Barth e Smith consideraram importantes também o 
compartilhamento de uma cultura e o auto reconhecimento da identidade étnica pelo grupo, para afirmação na sociedade. Barth entendeu que o reconhecimento da identidade do grupo deve ser legitimado pela sociedade envolvente como uma categoria que se distingue das demais, e Smith ampliou o conceito de grupo étnico, que passou também a abranger a territorialidade e o etnônimo, sendo este um distintivo do grupo e sem o qual a identidade étnica é incipiente e difusa. Essa afirmação de Smith demonstra a importância do etnônimo para as comunidades étnicas.

A emergência étnica, ou seja, a incorporação de uma identidade enquanto categoria política se refere à estratégia de visibilidade de uma comunidade que se considera como tal, acionada por uma razão ou por um interesse do grupo, atendendo, contudo, aos conceitos e critérios etnológicos e/ou legais, para fins de reconhecimento pela sociedade e/ou pelo Estado, o qual Cardoso de Oliveira (2005) chama de instância pública de reconhecimento jurídico".

Neste sentido, a categoria étnica de quilombola se incorpora à categoria de negro como um recurso político a mais na solução das demandas da comunidade. Na construção da identidade local e ao longo de sua história, a presença indígena e de brancos como vizinhos sempre foi uma constante na vida dos moradores de Massapê.

A definição por uma identidade quilombola somente veio à baila após a certificação da comunidade pela Fundação Cultural Palmares e a criação da segunda associação. Neste sentido, vale as palavras de Cardoso quando cita que:

Muitos autores têm demonstrado que o investimento em uma identidade étnica se mostra comum a muitos grupos sociais quando isso levará a ganhos políticos, como uma forma de estratégia política, com a intenção de mobilizar ganhos materiais ou simbólicos. Para os grupos que se auto definem como quilombolas, um dos elementos aspirado é o território (ALMEIDA, 1998). Arruti (1997) ressalta isso quando trata da emergência dos remanescentes indígenas e quilombolas (CARDOSO, 2008, p. 64-65).

Ainda constitui um mistério para muitos moradores a expressão quilombola. Esse adjetivo vem sempre acompanhado da possibilidade de estabelecer um diálogo com os poderes públicos - via ganhos materiais.

A identidade étnica de um grupo é a base para sua forma de organização, de sua relação com os demais grupos e de sua ação política. A maneira pela 
qual os grupos sociais definem a própria identidade é resultado de uma confluência de fatores, escolhidos por eles mesmos: de uma ancestralidade comum, formas de organização política e social a elementos linguísticos e religiosos ${ }^{5}$.

A Associação Brasileira de Antropologia (ABA), na tentativa de orientar e auxiliar a aplicação do Artigo 68 do Ato das Disposições Constitucionais Transitórias (ADCT) divulgou, em 1994, um documento elaborado pelo Grupo de Trabalho sobre Comunidades Negras Rurais em que se define o termo "remanescente de quilombo". Assim:

Contemporaneamente, o termo quilombola se refere a grupos que desenvolveram práticas de resistência na manutenção $e$ reprodução de seus modos de vida característicos num determinado lugar. Logo, prescinde de qualquer dependência a referências biológicas ou arqueológicas, ou mesmo de se ter a concepção de comunidade quilombola como grupos isolados ou de uma população estritamente homogênea.

Deste modo, comunidades remanescentes de quilombo são grupos sociais cuja identidade étnica os distingue do restante da sociedade. Assim:

A etnicidade é um aspecto do relacionamento social dos membros entre si, bem como entre grupos que se consideram distintos dos demais ou da sociedade envolvente, com quem se mantém interação regular. Os grupos étnicos tendem a ter mitos de origem comum e a incentivar a endogamia, mas essa endogamia pode ser mais contingência interativa gerada pelo convívio do que mesmo uma norma do grupo (BEZERRA, 2006, p. 26).

Falar em identidade étnica, implica na concepção de um processo de auto identificação bastante dinâmico, e que não se reduz a elementos materiais ou traços biológicos distintivos, como cor da pele, por exemplo"6.

Assim, o termo quilombo não é mais sinônimo de isolamento e fuga, e reemerge agora relacionado à resistência e à autonomia de populações

\footnotetext{
5 "Nesses primeiros anos do terceiro milênio, cresce o quantitativo de grupos remanescentes de quilombos brasileiros que acionam a estratégia de emergência da identidade étnica, visando ao reconhecimento da condição de quilombo pela sociedade envolvente e à consequente reivindicação do território titulado, nos termos do Art. 68 do ADCT/CF-1988. Em Pernambuco, também vem crescendo o número de quilombos emergentes. Nas reuniões do Grupo de Estudos Afro-Brasileiros, dirigido pelo Prof. Dr. Bartolomeu Figueirôa de Medeiros e vinculado ao Núcleo de Estudos e Pesquisas sobre Etnicidade-NEPE, da Universidade Federal de Pernambuco-UFPE, esse professor vem nos informando frequentemente sobre a lista crescente dos quilombos do Estado de Pernambuco em processo de reivindicação de território" (BARROS, 2006:11).

${ }^{6} \mathrm{http}: / /$ www.cpisp.org.br/comunidades/html/i_brasil_pe.html, acesso em 10/11/2017.
} 
negras rurais. Nesta nova configuração o que define o quilombo é o movimento de transição da condição de escravo para a de camponês livre. Tudo isso demonstra que a classificação de comunidade como quilombola não se baseia em provas de um passado de rebelião e isolamento, mas depende antes de tudo de como aquele grupo se compreende e se define. Atualmente, a legislação brasileira já adota este conceito de comunidade quilombola e reconhece que a determinação da condição quilombola advém da auto-identificação.

\section{Considerações finais}

As relações entre identidade a alteridade em Massapê se expressam pelo fato visível dos moradores locais se afirmarem enquanto pertencentes a uma comunidade majoritariamente negra. Os outros que podem ser os vizinhos os habitantes de Carnaubeira da Penha, os compadres de fora, mesmo apresentando traços de mestiçagem, se colocam como branco, indígena ou assim misturado. No fim fica sempre implícito o fato de ser não negro.

Por outro lado, os discursos orais dos moradores de Massapê, sempre falam de si como negros que não trazem a herança escrava, mas sim, com um passado de trabalho e, principalmente, de compra de terras. Afirmam e se colocam como proprietários de terras e trabalhadores rurais. 'Sempre trabalhei na terra, desde menina. Até hoje, vou todo dia pra roça'(Entrevista Judite, Massapê, 2009).

Independente dos casamentos interétnicos entre negros e indígenas, a orientação étnica se dá pelo local de moradia. Quem mora na terra dos indígenas é indígena. Quem mora no Massapê é negro. "Inútil é imaginar as muitas maneiras de se efetivar uma política de relações que não sejam matizadas pelo fator diferença racial, quando esta condição é algo transparente no cotidiano das pessoas"(OLIVEIRA JUNIOR, 1996, In: Leite, 2006).

Pertencer a Massapê também é balizado pelo fato de ter nascido na comunidade e pertencer a uma das duas famílias geradores: a de Joel Salvador ou a de Dioclécio Nogueira. As referências ao ter nascido lá estão sempre sendo argumentadas pelos moradores de Massapezinho, em Floresta.

Segundo Alfredo Wagner de Almeida (2002, p. 49) ao comentar sobre as relações intra e extra território é pertinente sua afirmação: 
No entanto, ao contrário do que imaginaram os defensores do "isolamento" como fator de garantia do território foram as transações comerciais da produção agrícola e extrativa dos quilombos que ajudaram a consolidar suas fronteiras físicas. Assim como se enganaram aqueles que viam no quilombo uma unidade racial homogênea, pois foram as suas inter-relações com outros grupos que possibilitaram sua reprodução social $e$ econômica (ALMEIDA, 2002:49).

Assim, podemos entender a entrada e o questionamento de uma nova categoria, a de quilombola, pelos moradores do Massapê. Não é apenas a busca por vantagens setoriais nas políticas sociais. Mas uma preocupação em entender a relação desta categoria com a identidade étnica de ancestralidade e, não somente, de ocupação da terra. Nas palavras de uma liderança quilombola de Massapê "Somos quilombolas. Nós viemos do Massapê. Não deixamos de ser negro e agricultor" (Entrevista Wandilene, Massapê, 2009).

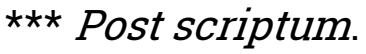

Em 2005, a comunidade se auto reconheceu e foi certificada pela Fundação Palmares.

Em 2007, foi criada a Associação Quilombola de Massapê.

Em 2009, foi elaborado o Relatório Antropológico do Território do Massapê.

Em 2010, foram iniciados os estudos para demarcação do Território Pankará. Neste momento, os moradores foram integrados a um novo processo de identificação. Agora como indígenas Pankará. Os casamentos interétnicos foram motivos, também, para esta nova situação. Vantagens surgiram desta nova condição: articulação dos moradores com 0 movimento indígena, criação de uma escola indígena no Massapê, abastecimento de água e multirões mensais para a reconstrução das casas que foram destruídas (MENDONÇA, 2013). 
Em 29 de junho de 2017, através da Portaria $n^{\circ}$ 193, a comunidade de Massapê deixou de se reconhecer e se autodefinir como remanescentes de quilombos.

\section{Referências Bibliográficas}

ALMEIDA, Alfredo Wagner Berno. 1996. Quilombos: sematologia face a novas identidades. In: CRUZ, Magno José et al (org). 1996. Frechal, terra de preto: quilombo reconhecido como reserva extrativista. São Luiz: SMDDH/CCN-PVN.

ARARIPE, André; NASCIMENTO, Erika. Sertão quilombola. $A$ formação dos quilombos no sertão de Pernambuco. Olinda: Centro de cultura Luiz Freire. 2008. $156 \mathrm{p}$.

ARRUTI, José Maurício P. Andim. Etnografia e história no mocambo: notas sobre uma "situação de perícia". In, Leite (Org.) 2005.

ATAÍDES, Jézus Marco, MACHADO, Laís Aparecida e SOUZA, Marcos André Torres de. Cuidando do patrimônio cultural. Goiânia: UCG, 1997.

BANDEIRA, Maria de Lourdes. Território negro em espaço branco: estudo antropológico de Vila Bela. São Paulo: Brasiliense, 1988.

BARBOSA, Luís de Lima. Em www.ceplac.gov.br/radar/artigos/ artigo.21htm. Acesso em 19/02/2009.

BEZERRA, Tercina Maria Lustosa Barros. O quilombo "Negros do Gilu" em Itacuruba: emergência etnoquilombola e territorialidade. Recife, UFPE, 2006. Dissertação de Mestrado.

BROWN e BARNETT. Dicionário de Sociologia. Versão on-line. www.prof2000.pt/users/dicsoc/soc_html-7k

CARDOSO, Luís Fernando Cardoso e. A construção local: direito e território quilombola na comunidade de bairro Alto, na ilha de Marajó - Pará. Tese de Doutorado. Florianópolis: UFSC, 2008.

Centro Cultural Luiz Freire. Sertão quilombola: a formação dos quilombos no sertão pernambucano. Olinda, 2008.

HARRISON, Lawrence E. w HUNTINGTON, Samuel P. A cultura importa: os valores que definem o progresso humano. Rio de Janeiro: Record, 2004. 
GUSMÃO, Neusa Maria Mendes de. Terra de pretos, terra de mulheres. Terra, mulher e raça num bairro rural negro. Brasília: Fundação Cultural Palmares, 1995.

LEITE, Ilka Boaventura. Negros no sul do Brasil: invisibilidade $e$ territorialidade. Florianópolis: Letras Contemporâneas, 1996.

OLIVEIRA JUNIOR, Geraldo Barboza de. Cultura e meio ambiente. Publicação eletrônica. www.kriterion.zlg.br/pg83.aspx. Acessado em 06/03/2009.

MENDONÇA, Caroline Farias Leal. Insurgência política e desobediência epistêmica: movimento descolonial de indígenas e quilombolas na Serra do Arapuá. (Tese Doutorado). Recife: Universidade Federal de Pernambuco, CFCG, Programa de Pód-Graduação em Antropologia. 2013.

MONTENEGRO, Antônio Torres, FERNANDES, Tânia Maria, organizadores, História oral um espaço plural, Recife: Universitária; UFPE 2001.

RAPCHAN, Eliane Seibrika. O uso da narrativa nas Ciências Sociais: algumas notas e reflexões acerca de suas possibilidades. In: MONTENEGRO, Antônio Torres e FERNANDES, Tania Maria (Org.). História Oral. um espaço plural. Recife: Universitária; UFPE, 2001.

Secretaria Municipal de Educação de Carnaubeira da Penha. Conhecendo melhor o nosso município. Apostilha/Mimeo. Carnaubeira da Penha, SMEC, 2002. 